\title{
Influence of canopy density on snow distribution in a temperate mountain range
}

\author{
J. I. López-Moreno ${ }^{1,2 *}$ and J. Latron ${ }^{2}$ \\ ${ }^{1}$ Department of Geosciences, University of Fribourg, Pérolles CH-1700, Switzerland \\ 2 Instituto Pirenaico de Ecología, CSIC, Campus de Aula Dei, Apdo 202, E-50.080 Zaragoza, Spain
}

\begin{abstract}
:
We analyse spatial variability and different evolution patterns of snowpack in a mixed beech-fir stand in the central Pyrenees. Snow depth and density were surveyed weekly along six transects of contrasting forest cover during a complete accumulation and melting season; we also surveyed a sector unaffected by canopy cover. Forest density was measured using the sky view factor (SVF) obtained from digital hemispherical photographs. During periods of snow accumulation and melting, noticeable differences in snow depth and density were found between the open site and those areas covered by forest canopy. Principal component analysis provided valuable information in explaining these observations. The results indicate a high variability in snow accumulation within forest areas related to differences in canopy density. Maximum snow water equivalent (SWE) was reduced by more than $50 \%$ beneath dense canopies compared with clearings, and this difference increased during the melting period. We also found significant temporal variations: when melting began in sectors with low SVF, most of the snow had already thawed in areas with high SVF. However, specific conditions occasionally produced a different response of SWE to forest cover, with lower melting rates observed beneath dense canopies. The high values of correlation coefficients for SWE and SVF $(r>0.9)$ indicate the reliability of predicting the spatial distribution of SWE in forests when only a moderate number of observations are available. Digital hemispherical photographs provide an appropriate tool for this type of analysis, especially for zenith angles in the range $35-55^{\circ}$.
\end{abstract}

KEY WORDS Snow distribution; snow water equivalent (SWE); temporal evolution patterns; mixed beech-fir stand; canopy density; sky view factor (SVF); principal component analysis (PCA)

\section{INTRODUCTION}

Snowpack is the dominant control over various environmental phenomena (i.e. hydrological, geomorphological, and biological processes) and economic activities (i.e. water resources management, tourism) in temperate and cold mountain areas (Bales and Harrington, 1995; Beniston, 2003; Breiling and Charamza, 1999; López-Moreno and Garcia-Ruiz, 2004). Several studies have analysed the factors (mainly topography and the exposure to different air masses) that determine the spatial distribution of snowpack, which commonly shows great variability over short distances (Elder et al., 1998; Yang and Woo, 1999; Erxleben et al., 2002; Anderton et al., 2004; López-Moreno and Noguès-Bravo, 2005, 2006). Others highlight the role of the forest canopy in controlling snow accumulation (through interception and subsequent evaporation/sublimation) and melting processes (by affecting various elements of the snow energy balance). Thus, spatial variations in the density of the forest canopy can lead to significant variations in the spatial distribution of snowpack, which in areas beneath a dense forest canopy can be as little as $40-50 \%$ of the snowpack thickness in open areas (Bernier and Swanson, 1992; Pomeroy

\footnotetext{
* Correspondence to: J. I. López-Moreno, Department of Geosciences, University of Fribourg, Pérolles CH-1700, Switzerland.

E-mail: Ignacio.Lopez@archi.unige.ch
}

and Gray, 1995; Pomeroy et al., 1998; Koivusalo and Kokkonen, 2002; Murray and Buttle, 2003; Lundberg et al., 2004). Recently, Talbot et al. (2006) reported that snow dynamics are more highly dependent on stand density than on aspect.

Although snowmelt in the Pyrenees is of great hydrological importance (López-Moreno and GarcíaRuiz, 2004), few studies have analysed the distribution and seasonal evolution of snowpack (García-Ruiz et al., 1986; López-Moreno, 2005a,2005b; López-Moreno and Nogués-Bravo, 2005). In the present study area, the effect of forest canopy on snow cover has yet to be studied, despite the existence of large areas of forest above the wintertime and early springtime snowline at $\sim 1600-2000 \mathrm{~m}$ above sea level (a.s.l.).

Research on this topic is important because it may help to obtain a better understanding of the hydrological response of Pyrenean headwaters to snowmelt and provide guidelines for forest management practices that are in agreement with the optimization of water resources. Moreover, the extent of forests in Mediterranean mountain areas is expected to increase in the future as a result of two factors: (i) a reduction in grazing within the subalpine belt to enable the development of forests until the natural treeline is recovered (Montserrat, 1992); (ii) an increase in forest density and elevation of the treeline related to predicted warming over the coming 
decades (Essery, 1998; Houghton et al., 2001; Beniston, 2003).

Most previous studies that have dealt with the effect of forests on snowpack behaviour have focused on highlatitude environments in North America, Scandinavia, the former Soviet republics, and northern Japan; however, it is necessary to check whether the findings obtained for those areas are valid with regard to the Pyrenees (north of the Iberian Peninsula, $40^{\circ} \mathrm{N}$ ), where the general climatic conditions are very different to those of earlier studies. In addition, most of the earlier studies tend to compare open and forested sites, with few analyses of variability in snow accumulation within forested sites.

In this context, we carried out intensive snow depth and density sampling within a mixed beech-fir stand that was highly variable in canopy density, including a number of clearings of approximately twice the canopy height $H$. The study site was chosen within a flat area that is homogeneously exposed to solar radiation in order to isolate, as much as possible, the impact of forest cover on snow distribution with regard to other factors. The measurements obtained were related to the density of the forest canopy, which was quantified by the sky view factor (SVF) obtained from hemispherical digital photographs.

The objective of this paper is to analyse the effect of forest density on the evolution of snowpack during a complete accumulation and melting period within a Pyrenean mountain range. This study focuses on:

1. highlighting the significant variability in snowpack, even over very short distances;

2. evaluating the usefulness of SVF in assessing the spatial distribution of snow depth at forested sites;

3. quantifying the interception evaporation/sublimation capacity of the stand throughout the snow season, with special focus on the impact of these factors on the maximum snow water equivalent (SWE);

4. relating the observed variability in snowpack to the measured density of forest canopy;

5. using principal component analysis (PCA) to obtain representative patterns of snow accumulation and melting in both open areas and areas beneath forest canopies.

\section{STUDY SITE}

The study site is located in a forest stand at $1550 \mathrm{~m}$ a.s.l., close to the divide between the Aragon (Spain) and Aspe (France) Valleys in the western Pyrenees. The high altitude and exposure to the Atlantic and northern air masses results in high precipitation $\left(1700 \mathrm{~mm} \mathrm{year}^{-1}\right)$, mainly during winter and spring. High rates of precipitation and low temperature during winter promote significant snow accumulation that usually melts from March to the beginning of May; however, melting events can occur at any time during the snow period, even during the coldest months (López-Moreno, 2005b).
The study site is a flat area of 3 ha, mostly covered by a mixed beech-fir forest. This type of mixed forest is commonly found upon humid slopes in the Pyrenees. The impact of recent human activities on the stand is very low; thus, the stand comprises old trees with a mean height of approximately $20 \mathrm{~m}$. There is almost no undergrowth within the forest, with only scattered short shrubs growing in clearings. Soils appear to be homogenous within the studied forest stand.

\section{DATA AND METHODS}

Snow depth and density were measured from early December 2004 to the end of April 2005. Twenty surveys were performed over this 5-month period, with a mean interval of 7 days between measurements; the sampling interval varied with meteorological conditions. Snow depth was measured manually using a steel probe along the six transects defined above according to cover characteristics to sample the extremes in canopy density observed within the area. Forty-two sites were measured in total during each survey. Each depth measurement involved three replicates within a $50 \mathrm{~cm}$ diameter of the initial measurement to negate the effect of local anomalies related to microtopography, stones, branches, or the erroneous perception of reaching the ground surface when encountering a frozen layer. The final depth value was derived by averaging the four measurements, while rejecting those measurements with a bias greater than $25 \%$ of the other three measurements. Snow depth was also measured at a site close to the main study area that was unaffected by forest (opening $>5 H$ ).

During each survey, snow density was measured in six sectors of contrasting forest cover and snow depth. Snow density was determined by weighing a known volume of snow sampled using a $5 \mathrm{~cm}$ diameter PVC tube that was inserted vertically into the snowpack. At least two measurements of density were taken at each point. The SWE was obtained as the product of snow depth and density. The absence of a clear pattern in density variations between the six measurement points led us to use a mean value of snow density during each survey.

Temperature and incoming solar radiation were measured using a HOBO sensor (http://.onsetcomp/Products/ Product_Pages/weatherstation/silicon_pyranometer.html) located within an opening in the sampled stand.

The density of the forest canopy was estimated from hemispheric digital photographs taken using a fish-eye lens. Previous studies provide numerous examples of the use of vertical hemispheric images in obtaining measurements of canopy density, light and energy distribution below the canopy, and the interception evaporation/sublimation capacity or canopy structure (e.g. Llorens and Gallart, 2000; Englund et al., 2000; Hardy et al., 2004; Leblanc et al., 2005). In this study, we photographed the canopy vertically at each point at which we measured the snow depth.

We subsequently processed the digital photographs using GLA software (Gap Light Analyzer; Frazer et al., 

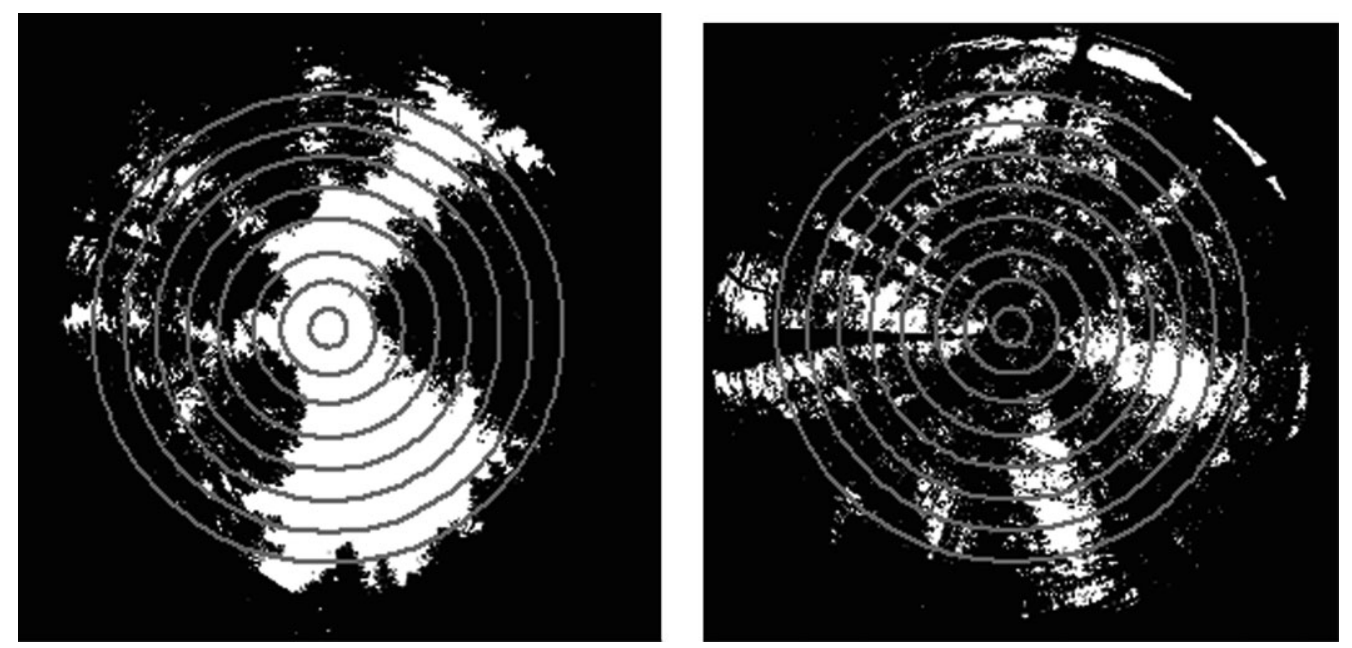

Figure 1. Hemispherical photographs from two points with contrasting SVF. Concentric circles indicate the portion of the sky hemisphere included when zenith angles of $5^{\circ}, 15^{\circ}, 25^{\circ}, 35^{\circ}, 45^{\circ}, 55^{\circ}, 65^{\circ}$, and $75^{\circ}$ are considered

1999) to obtain the SVF, i.e. the percentage area of the sky hemisphere above the effective horizon. Thus, SVF represents the weighted gap fraction from the forest floor (Hellstrom, 2000). Lundberg et al. (2004) note that the use of SVF in analysing variability in snow distribution provides an accuracy comparable to other measurements of canopy density, such as leaf area index. A grey-scale threshold was used to discriminate between forest canopy and sky (Lundberg et al., 2004). Correlation analysis indicated a low impact of the threshold value on relative differences in SVF between the measurement points.

GLA software was used to calculate SVF for various zenith angles from the vertical (Figure 1). In this way, snow cover measured at each point was related to canopy density for cumulative angle amounts $\left(5-75^{\circ}\right)$ to assess the impact of canopy density on the obtained results. Higher zenith angles $\left(>75^{\circ}\right)$ were not appropriate because they introduced elements of the surroundings (ground and vegetation) into the SVF calculation.

Differences in the measured patterns of snow accumulation and melting as a consequence of forest cover were analysed via PCA. The evolution of each of the 42 SWE series during the 20 surveys was taken as a factor in the analysis. PCA is widely used to determine the most general temporal and spatial patterns of different climatic variables, and it enables common features to be identified and specific local characteristics to be determined (Richman, 1986). PCA reduces a large number (42 in this study) of interrelated cases to several independent principal components (PCs) that capture the majority of the variance in the original dataset (Hair et al., 1998).

A correlation matrix was selected for the analysis because it provided a more efficient representation of the variance in the dataset. The criterion for component selection was made according to an eigenvalue $>1$ (Hair et al., 1998). Invariable spatial patterns (Richman, 1986; White et al., 1991) were then obtained using varimax rotation. The rotation procedure enables a clearer separation of components that maintain their orthogonality (Hair et al.,
1998) and concentrates the loading for each PC onto the most influential variables.

\section{RESULTS}

Snow accumulation and melting dynamics

Figure 2 shows the evolution of climatic variables, as well as snow depth and SWE. Figure 2a shows the temperatures recorded during the study period. Conditions from the end of February to mid March were very cold, with maximum temperatures only exceeding $0{ }^{\circ} \mathrm{C}$ by a small amount on a limited number of days. Later in the study period, temperatures increased markedly, with maxima exceeding $10^{\circ} \mathrm{C}$ and minima around $0{ }^{\circ} \mathrm{C}$. In mid April, the recorded temperature increase was more pronounced, with temperatures at the end of the study period close to $20^{\circ} \mathrm{C}$ and a progressive decrease recorded in freezing events. Incoming radiation maintained a nearlinear increase throughout the period.

Figure $2 \mathrm{~b}$ shows the 42 series of snow depth measurements and their mean value (thick line) plus/minus one standard deviation (shaded area). The main snowfalls occurred from the end of December to the beginning of March, when the maximum depth was recorded. At this time, snow pack depth exceeded $2 \mathrm{~m}$ at some locations and was less than $1 \mathrm{~m}$ at others. Following this maximum, the snow depth decreased steadily despite a number of moderate accumulation events during mid April. A high spatial variability in snow depth was observed throughout the entire period.

Snow density showed low and constant values $\left(\sim 0.3 \mathrm{~g} \mathrm{~cm}^{-3}\right)$ from December to the end of February. Higher densities were only observed during the first two surveys, and reflect the metamorphism of a thin snowpack that accumulated at the end of November. Density increased rapidly from March, exceeding $0.5 \mathrm{~g} \mathrm{~cm}^{-3}$ in April. The combination of snow depth and density dynamics defined the evolution of SWE (Figure 2c). Maximum values of SWE varied in the range 

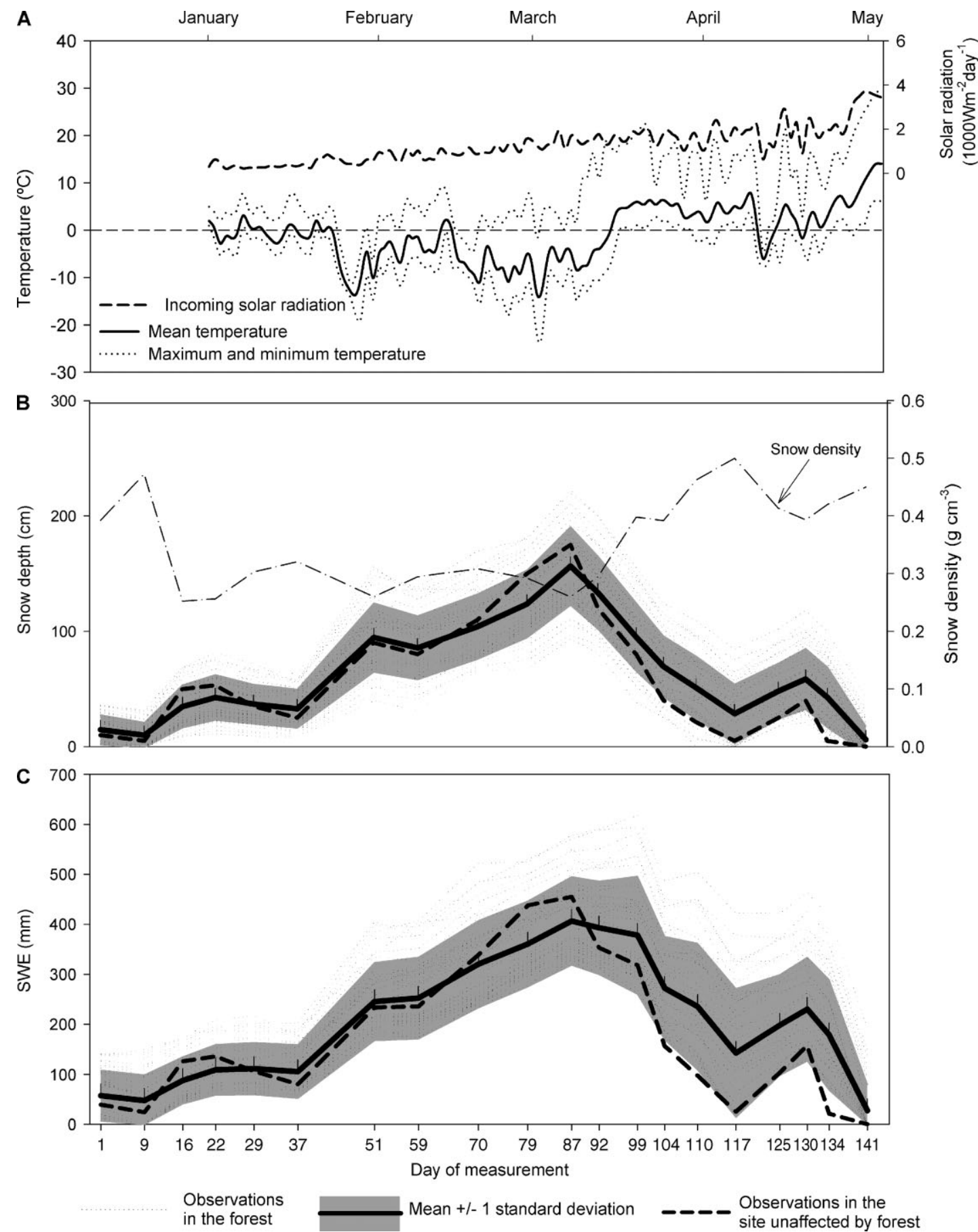

Figure 2. Evolution in climate variables and snowpack over the study period: (a) incoming solar radiation and temperature; (b) snow depth and density; (c) SWE

200-600 mm, although most observations (plus/minus one standard deviation of the average) were in the range $300-500 \mathrm{~mm}$. Melting began in the second half of March, at which time differences in SWE recorded throughout the stand were maintained or even increased. The highest melting rates occurred at the beginning of the melting period $\left(17.7 \mathrm{~mm} \mathrm{day}^{-1}\right.$ during days $\left.99-104\right)$ and at the end of April $\left(21.7 \mathrm{~mm} \mathrm{day}^{-1}\right.$ during days 134-141), coinciding with the highest temperatures.

The dashed lines in Figure $2 b$ and $c$ represent the evolution of snowpack within an equivalent environment (altitude and exposition), but for the open site. Here, the snowpack behaved quite differently to that in the forest plot. During the accumulation period, snow depth values approximately conformed to or slightly exceeded the mean value recorded in the forest, but snowpack melted noticeably faster in the open area than in the forest plot. Thus, the highest melting rates recorded during the study were obtained for the open site: $32 \mathrm{~mm} \mathrm{day}^{-1}$ (days 99-104) and $34 \mathrm{~mm} \mathrm{day}^{-1}$ (days 130-134).

\section{Effect of canopy density on snow distribution}

Figure 3a shows variations in SWE measured at each point during the 20 surveys, along with the corresponding 


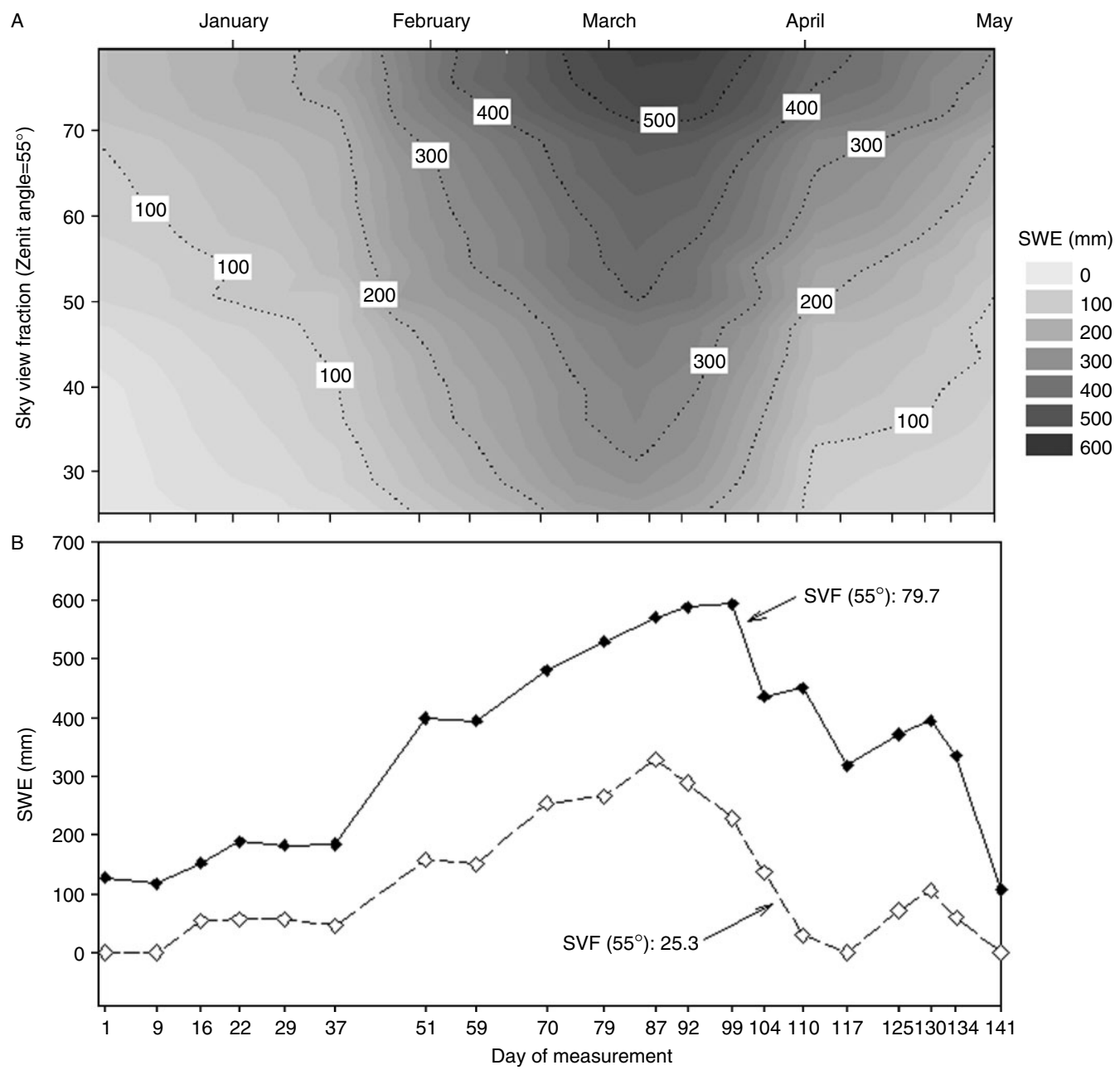

Figure 3. Relationship between SWE and SVF (zenith angle $55^{\circ}$ ) during the 20 snow surveys: (a) all surveyed points; (b) evolution of SWE at the points with the highest (79.7) and lowest $(25 \cdot 3)$ SVF

SVF (zenith angle of $55^{\circ}$ ). The variability in snow distribution observed across the study area (Figure $2 b$ and c) is clearly related to forest density: denser canopies are associated with lower SWE over the entire accumulation and melting period. Variations in SVF (25.3-79.7\%) led to differences in SWE that sometimes exceeded $50 \%$, as is clearly evident in Figure $3 b$.

Figure 4 shows the relationship between the maximum SWE at each point and its corresponding SVF (zenith angle $55^{\circ}$ ). The relationship is approximately linear, with

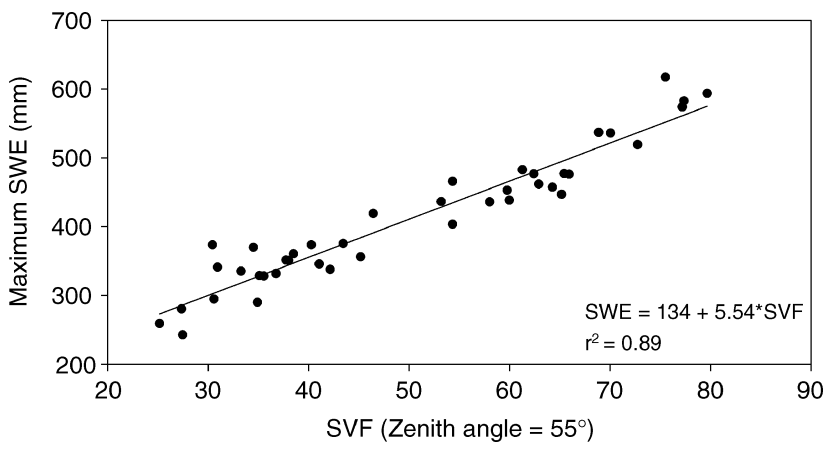

Figure 4. Correlation between SVF (zenith angle $55^{\circ}$ ) and maximum SWE observed at each of the 42 surveyed points
SVF accounting for $\sim 90 \%$ of the observed variance in SWE.

We then tested for a consistent relationship between SWE and SVF (ascertained at 42 points). Figure 5 shows, for each day of the survey, the slope of the regression between SWE and SVF and the corresponding correlation coefficient obtained for various zenith angles $\left(5-75^{\circ}\right)$. Correlation coefficients are very high for the accumulation period, with a slight decrease observed throughout the melting period, followed by a marked decrease in correlation at the end of the study period related to the occurrence of a number of points where snowpack had completely disappeared. The degree of correlation tended to increase with zenith angle: the strongest correlations $(r>0.9)$ were obtained for zenith angles ion excess of $30^{\circ}$. For angles above $40^{\circ}$, the degree of correlation improved only slightly, whereas some of the calculated correlation coefficients show a slight decrease for angles above $55^{\circ}$ (data not shown). The slope of the relationship between SWE and SVF is an indication of the observed change in SWE (millimetres) for a $1 \%$ increment in SVF. In Figure 5, seasonal variability in the slope value (i.e. of the influence of forest on SWE) is clearly apparent. The two highest gradients were recorded 


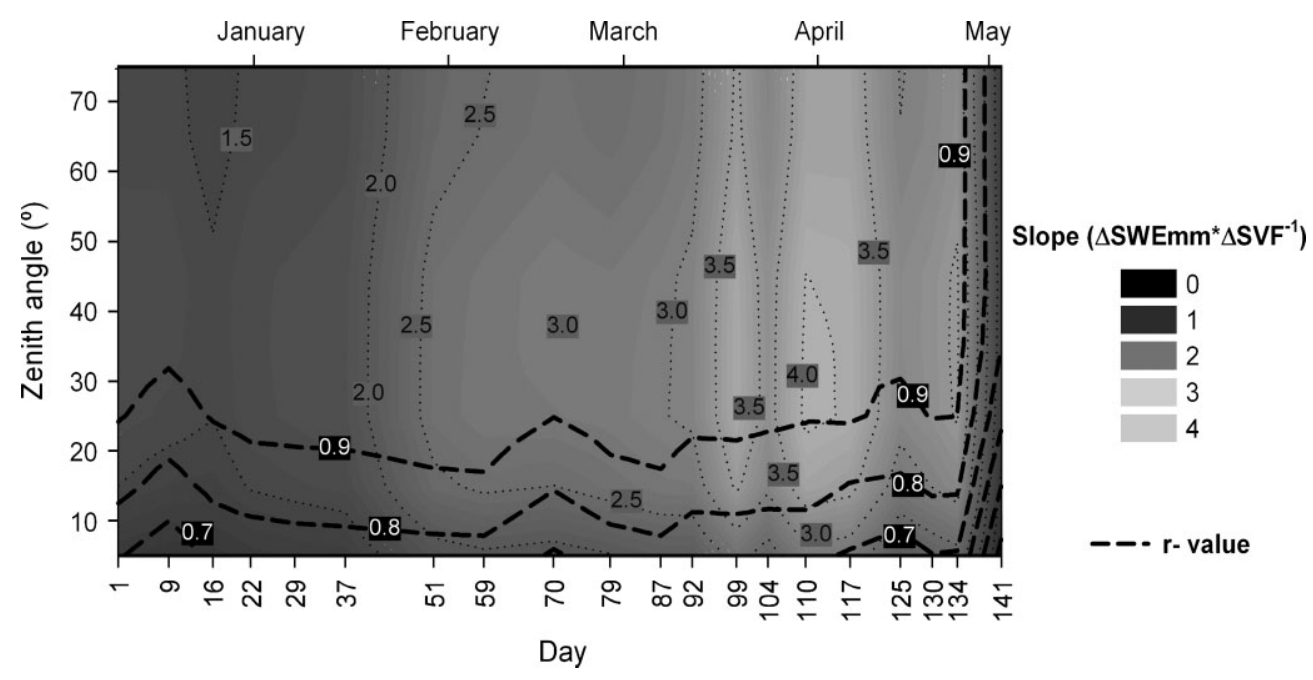

Figure 5. Correlation coefficients and slope of the relationships between SWE and SVF for different zenith angles

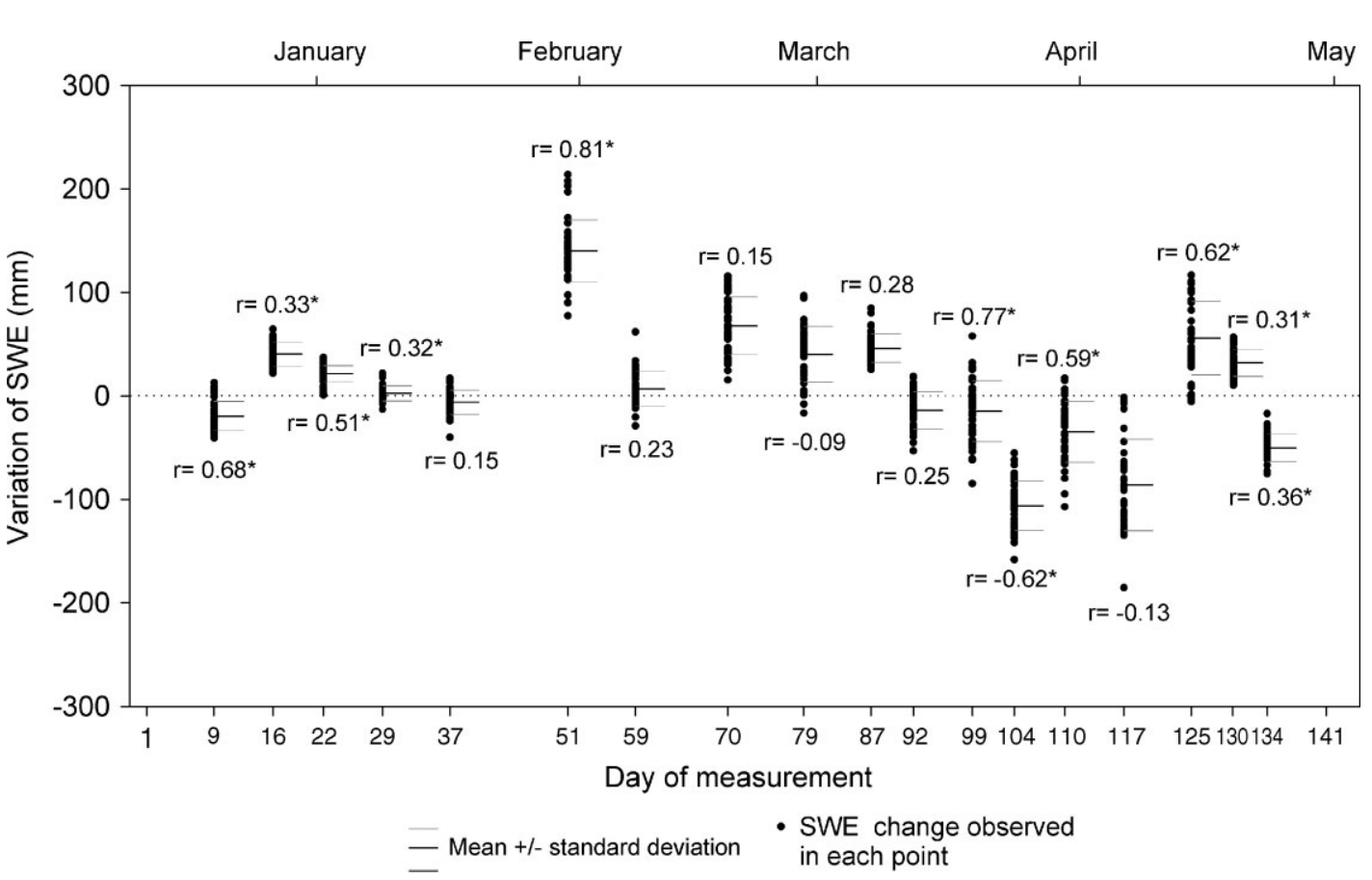

Figure 6. Observed change in SWE at each point between successive snow surveys and relationship to SVF (zenith angle $55^{\circ}$ )

in mid March $\left(\Delta \mathrm{mmSWE} \times \Delta \mathrm{SVF}^{-1}>3\right)$ and early April $\left(\Delta \mathrm{mmSWE} \times \Delta \mathrm{SVF}^{-1}>3.5\right)$. The former period coincided with the highest recorded values of SWE, whereas the latter is linked to conditions immediately following the main melting period. Over the entire study period, maximum slopes were obtained for zenith angles of $25-50^{\circ}$.

The effect of forest canopy on short-term SWE dynamics is illustrated in Figure 6, which shows the observed changes in SWE (at the 42 points) between two successive surveys and their relationship with SVF (zenith angle $55^{\circ}$ ). The existence of both positive and negative correlations and the high degree of variation in the correlation coefficients indicates the complexity of the effect of forest canopy on the evolution of SWE. In general, most of the significant correlations show positive trends, indicating less accumulation or greater melting under dense canopies. All accumulation periods show positive trends. The strongest correlation was found for the end of January, after the main snow accumulation period and following a 30-day dry spell. SWE increased during days $37-51$ over the range $82-223 \mathrm{~mm}$, and was closely related to SVF. Subsequent to this, we observed a 50-day period with no significant correlations, coincident with continuous moderate increases in SWE and temperatures below $0{ }^{\circ} \mathrm{C}$. Throughout this period, a high load of snow upon branches was observed during snow surveys, and this possibly limited the interception evaporation/sublimation capacity of the canopy. During melting periods, correlations were again mainly positive, although a number of significant negative trends (see days 104 and 110) indicate that SWE thawed more rapidly in clearings than under forest under specific melting conditions. 


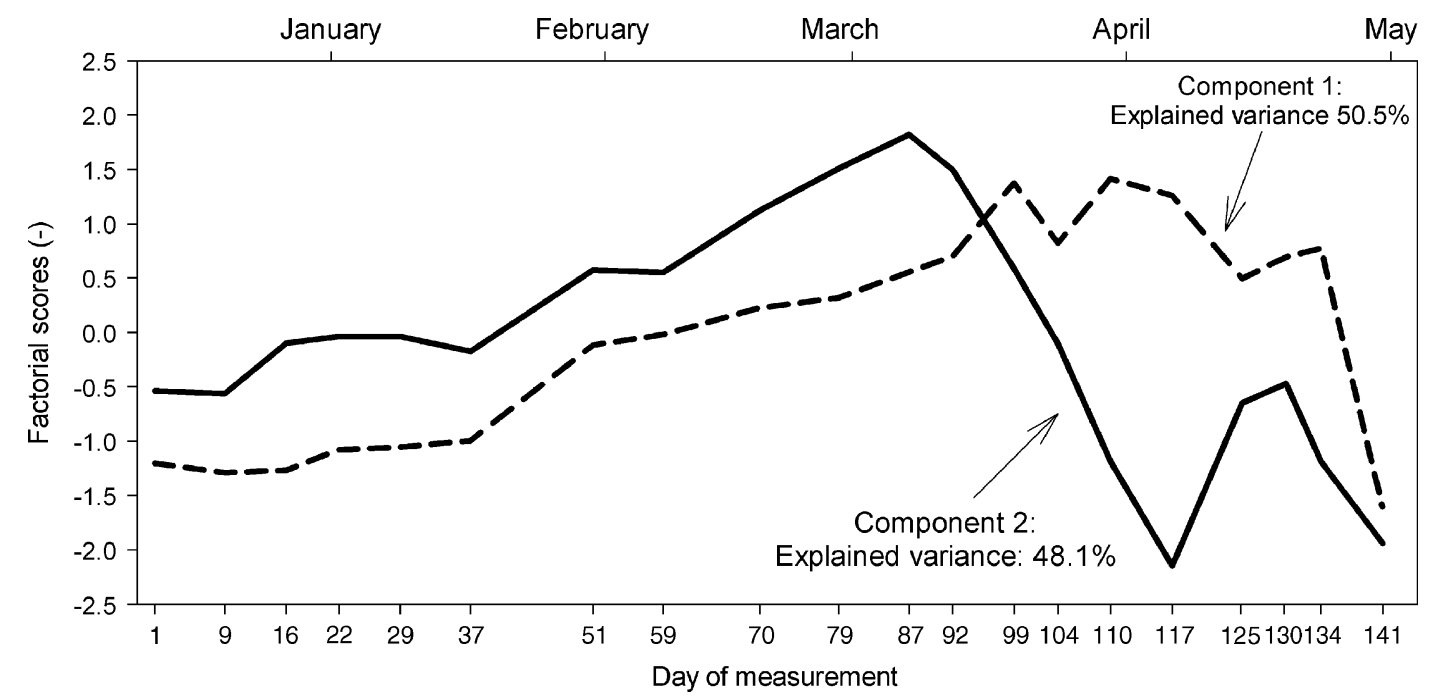

Figure 7. Synthetic series of SWE evolution obtained from PCA
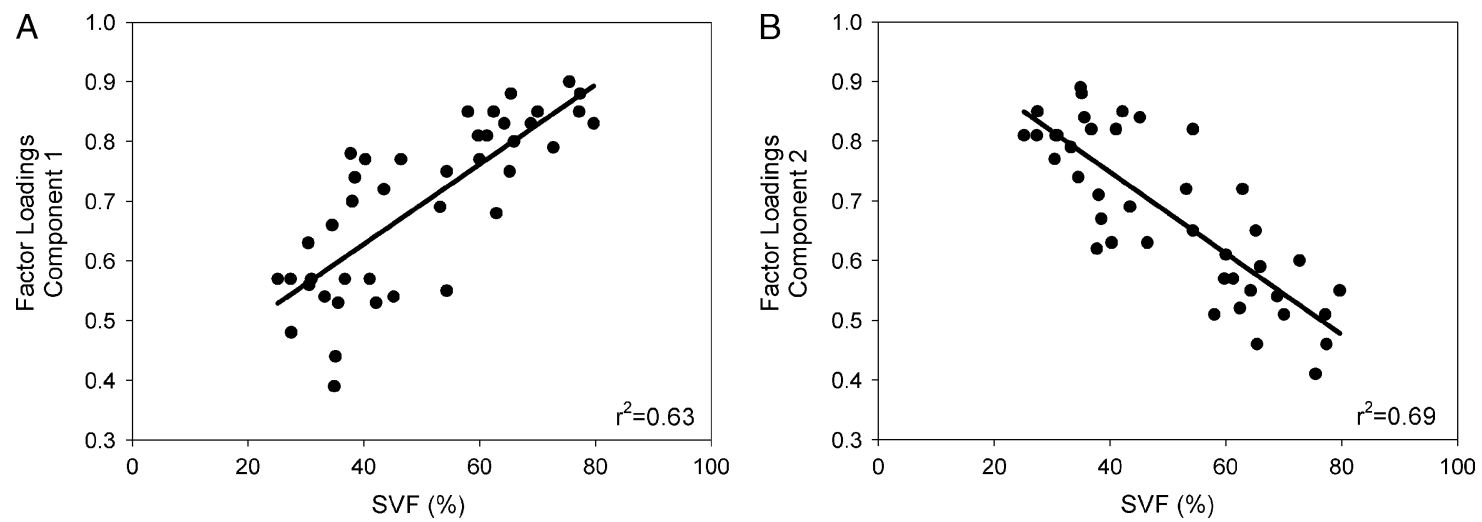

Figure 8. (a) Correlation between $\mathrm{C} 1$ and SVF (zenith angle $55^{\circ}$ ). (b) Correlation between $\mathrm{C} 2$ and SVF (zenith angle $55^{\circ}$ ). Factor loadings indicate correlation of the SWE evolution observed at each point with the evolution of each PC

Effect of forest canopy density on patterns of snow evolution

The results presented above confirm that variable canopy density leads to noticeable changes in snow accumulation and melting dynamics in the stand analysed, as well as enhancing the observed heterogeneity in the evolution of SWE at the 42 sampling locations. We used PCA to identify the main patterns of SWE evolution in the study area. The analysis yielded two synthetic series (Figure 7) that explain most of the observed variance in the 42 accumulation and melting series shown in Figure 2c. The first component (C1) explains $50.5 \%$ of the variance, and its evolution synthesizes the accumulation and melting patterns of points with a low density of forest cover. This conclusion is supported by the strong positive correlation between the factor loadings of $\mathrm{C} 1$ and SVF, as shown in Figure 8a. The factor loadings indicate the degree of correlation between SWE evolution observed at each point and the evolution of each $\mathrm{PC}$. The second component ( $\mathrm{C} 2 ; 48.2 \%$ of variance) represents densely forested sectors, as it shows a negative correlation with SVF (Figure 8b). The two components show clear differences in their evolution. The first component $(\mathrm{C} 1$; low canopy density) reached the maximum
SWE at the beginning of March and remained stable until April, when temperatures rose well above $0{ }^{\circ} \mathrm{C}$ and solar radiation increased. In contrast, $\mathrm{C} 2$ reached the maximum SWE shortly before $\mathrm{C} 1$ and began to decrease immediately thereafter. In this case, the decrease in SWE coincided with the first period for which mean temperature exceeded $0{ }^{\circ} \mathrm{C}$. It is interesting to note that, at the end of March, when melt began in areas with low cover (decrease in $\mathrm{C} 1$ ), the majority of the snowpack beneath dense forest canopy had thawed.

\section{DISCUSSION AND CONCLUSIONS}

We have analysed the effect of forest canopy density on the distribution of snow pack and its evolution over a complete accumulation and melting period. We achieved this by selecting a stand of forest with homogeneous topographic characteristics to isolate the impact of SVF variability with regard to other possible factors.

The main outcomes of the study are listed below.

1. We found a clear difference in the behaviour of snowpack evolution between an open site and sites within the forest stand. PCA enabled us to identify two 
principal uncorrelated patterns from a large number of available series (42 sites). Correlation between factor loadings and SVF shows that one of the patterns is clearly associated with open areas, whereas the second pattern relates to areas covered by forest. The open site accumulated less snow than the most favourable sites in the forest (those with the highest SVF). These points correspond to clearings (width of $2 \mathrm{H}$ ) within which the canopy intercepts almost no snow and where the surrounding canopy acts as a shelter to wind, reducing wind drift processes as well as the effect of turbulent energy-exchange fluxes (Bernier and Swanson, 1992; Pomeroy et al., 2002; Murray and Buttle, 2003). Excluding forest clearings, SWE measured in the open site clearly exceeded values for forested areas during the accumulation period. Differences in SWE between open and forested sites exceeded $40 \%$, similar to values obtained for conifer forests in various environments. Lundberg et al. (2004) estimated that forests can act to reduce the winter water budget up to $40 \%$, Pomeroy and Gray (1995) calculated that losses in annual snowfall related to sublimation fall in the range $25-45 \%$, and Niu and Yang (2004) reported that, in areas beneath a forest canopy, annual snowfall losses are reduced by $30-40 \%$. The melting rate observed in the open site was higher than that for the forest, leading to a rapid depletion of the snowpack.

2. Large differences in SWE were found among the 42 surveyed points within the forest, and a high degree of variability was observed among the different patterns of temporal evolution in SWE. Measured differences were closely related to the density of the forest canopy: dense forest cover intercepted much of the snowfall and commonly resulted in an earlier (see Figure 7) thaw and higher melting rates (see Figure 6), and values of SWE were lower under such areas over the entire measurement period. Differences in the maximum observed SWE have a significant hydrological relevance, as they are directly related to the amount of water available for melting. In this study, maximum differences in SWE exceeded 50\% for the most extreme situations of SVF. Considering the range in SVF equivalent to plus/minus one standard deviation, the reduction was around $25 \%$. Relevant differences were also observed at the beginning of the melting period, probably because of the combined effect of interception evaporation/sublimation during the accumulation period and differential melting behaviour according to canopy density. At the start of the melting period, melting was commonly observed at points with lower SVF, whereas for points with high SVF the SWE remained constant for at least two more weeks. To assess the snow interception evaporation/sublimation capacity of the forest canopy, therefore, it is necessary to ensure that measurements correspond to the maximum accumulation period. Otherwise, the effect of the forest canopy on melting processes is also included in the data, leading to an overestimation of the snow interception evaporation/sublimation capacity.

3. We found consistent linear relationships between SWE and SVF, with most correlation coefficients exceeding 0.9 . This finding is in accordance with results obtained for climatically varied areas in Canada (Pomeroy et al., 2002), Japan (Lundberg et al., 2004), and Sweden (Mellander et al., 2005), which suggests that the use of forest density as a predictor variable of SWE in snow distribution models may provide realistic results for stands of similar vegetation characteristics and exposure to those analysed in the present study. The impact of species types and exposure should be addressed in future research, as it may introduce variations into the relationships shown here (Hedstrom and Pomeroy, 1998; Lundberg and Halldin, 2001; Talbot et al., 2006).

4. When analyses were carried out for individual events or on a short-term basis, we uncovered interesting uncertainties related to the effect of forest canopy on accumulation and melting dynamics. Figure 6 shows clear differences in the role of the canopy in snow interception evaporation/sublimation and in melting processes, which may act in a contradictory way (positive and negative coefficients). This finding could explain the slow but progressive weakening of correlation coefficients during the melting period. Changes in the canopy's capacity for snow interception evaporation/sublimation appear to be related to the snow load on the branches at the time of snowfall. Maximum interception evaporation/sublimation was recorded during a period of intense snowfall following a long dry spell; however, during February, the snow load remained on branches and a low interception capacity was recorded during snowfall events at this time. The influence of the previous load on snowfall interception capacity, which has been demonstrated experimentally (Hedstrom and Pomeroy, 1998), may explain observations (Keller and Strobel, 1982; Mellander et al., 2005) that indicate smaller differences in SWE between forested and non-forested areas during years with substantial snow accumulation. In contrast, Lundberg et al. (2004) reported similar interception evaporation/sublimation fractions for years with high and low precipitation. Differences in the impact of forest canopy density during thawing periods should, therefore, be related to the dominant processes that generate melt during the different periods. In this study, correlations between variations in SWE and SVF (Figure 6) are generally positive during melting periods, suggesting a higher melting rate under forest cover. This can be explained by the large amount of longwave energy advected by the trees once temperatures increase above $0^{\circ} \mathrm{C}$, and by the lower albedo in these sectors due to the accumulation of litter upon the snow (Faria et al., 2000). However, melting rates were lower beneath dense forest cover during certain periods (days 104-110; Figure 6). Previous studies consider that this may occur when melting is associated with 
rainfall over the snowpack (Marks et al., 1998) during days with extremely high levels of incoming solar radiation or high-wind events, which act to enhance turbulent energy fluxes (Metcalfe and Buttle, 1995; Pomeroy and Granger, 1997; Murray and Buttle, 2003; Talbot et al., 2006). These factors potentially explain the results presented above, as well as the fact that the highest melting rates were observed in the open site; these factors have a greater impact in open sites than in sites with openings of $H$ to $2 H$ (Hellstrom, 2000; Koivusalo and Kokkonen, 2002; Melloh et al., 2002). These uncertainties observed at the scale of single events did not affect the significantly high degree of correlation between SWE behaviour and SVF during the accumulation and melting periods, but they do suggest that specific climatic conditions may have noticeably altered the results of the present study. Thus, long-term analysis of the spatial variability and evolution patterns of SWE are required for a better understanding of the hydrological behaviour of completely or partially forested catchments that are seasonally controlled by snowfall and snowmelt processes.

5. SVF data obtained from hemispherical photographs were used successfully to explain the observed spatial variability in SWE within a forest plot. This is in agreement with previous studies that also focused on the analysis of spatial variation in snow distribution within forests (Lundberg et al., 2004). However, the results obtained in our study suggest that it is necessary to take into account potential uncertainties when conducting an analysis using SVF values related to varying zenith angles. In fact, when different zenith angles were used to determine SVF, we observed clear differences in the slope of the trend between SVF and SWE and the value of the corresponding correlation coefficients. Our results indicate that zenith angles in the range $35-55^{\circ}$ are optimal for linking forest cover to SWE distribution.

\section{ACKNOWLEDGEMENTS}

This study was supported by the following research projects funded by CICYT of the Spanish Ministry of Science and Technology: PIRIHEROS (REN 200308678/HID, CGL2005-04508/BOS) and CANOA (CGL 2004-04919-C02-01). Juan Ignacio López-Moreno was supported by a postdoctoral fellowship from the Spanish Ministry of Education, Culture and Sports. Jérôme Latron benefited from a CSIC research contract within the I3P Programme. We are particularly grateful to the numerous colleagues and friends who helped us during the measurement surveys, and to the 'Parc National des Pyrénées' and the Somport Nordic Ski Resort for the use of their facilities and permission to work in the study area.

\section{REFERENCES}

Anderton SP, White SM, Alvera B. 2004. Evaluation of spatial variability in snow water equivalent for a high mountain catchment. Hydrological Processes 18: 435-453.

Bales RC, Harrington RF. 1995. Recent progress in snow hydrology. Reviews of Geophysics 33: (Suppl.): 1011-1020.

Beniston M. 2003. Climatic change in mountain regions: a review of possible impacts. Climatic Change 59: 5-31.

Bernier PY, Swanson RH. 1992. The influence of opening size on snow evaporation in the forests of Alberta Foothills. Canadian Journal of Forest Research 23: 239-244.

Breiling M, Charamza P. 1999. The impact of global warming on winter tourism and skiing: a regionalised model for Austrian snow conditions. Regional Environmental Change 1: 4-14.

Elder K, Rosenthal W, Davis R. 1998. Estimating the spatial distribution of snow water equivalence in a montane watershed. Hydrological Processes 12: 1793-1808.

Englund SR, O'Brien JJ, Clarck DB. 2000. Evaluation of digital and film hemispherical photography and spherical densitometry for measuring forest light environments. Canadian Journal of Forest Research 30: 1999-2005.

Erxleben J, Elder K, Davis R. 2002. Comparison of spatial interpolation methods for estimating snow distribution in the Colorado Rocky Mountains. Hydrological Processes 16: 3627-3649.

Essery R. 1998. Boreal forests and snow in climate models. Hydrological Processes 12: $1561-1567$.

Faria DA, Pomeroy JW, Essery RLH. 2000. Effect of covariance between ablation and snow water equivalent on depletion of snow-covered area in a forest. Hydrological Processes 14: 2683-2695.

Frazer GW, Canham CD, Lertzman KP. 1999. Gap Light Analyzer (GLA). Version 2.0: imaging software to extract canopy structure and gap light transmission indices for true color fisheye photographs, user manual and program documentation. Simon Fraser University/Institute of Ecosystem Studies, Burnaby, BC/Millbrook, NY.

García-Ruiz JM, Puigdefábregas J, Creus J. 1986. La acumulación de la nieve en el Pirineo Central y su influencia hidrológica. Pirineos 17: 27-72.

Hair JF, Anderson RE, Tatham RL, Black WC. 1998. Multivariate Data Analysis. Prentice Hall: New York.

Hardy JP, Melloh R, Koening G, Marks D, Winstral A, Pomeroy JW, Link T. 2004. Solar radiation transmission through conifer canopies. Agricultural and Forest Meteorology 126: 257-270.

Hedstrom NR, Pomeroy JW. 1998. Measurements and modelling of snow interception in the boreal forest. Hydrological Processes 12: $1611-1625$.

Hellstrom RA. 2000. Forest cover algorithms for estimating meteorological forcing in a numerical snow model. Hydrological Processes 14 3239-3256.

Houghton JT, Ding DJ, Griggs M, Noguer M, van der Linden PJ, Dai X, Maskell K, Johnson CA (eds). 2001. Climate Change 2001: The Scientific Basis. Contribution of Working Group I to the Third Assessment Report of the Intergovernmental Panel on Climate Change. Cambridge University Press: New York.

Keller HM, Strobel T. 1982. Water and nutrient discharge during snowmelt in subalpine areas. In Hydrological Aspects of Alpine and High-Mountain Areas. IAHS Publication No. 138. IAHS Press: Wallingford; 331-341.

Koivusalo H, Kokkonen T. 2002. Snow processes in a forest clearing and in a coniferous forest. Journal of Hydrology 262: 145-164.

Leblanc SG, Chen JM, Fernandes R, Deering DW, Conley A. 2005. Methodology comparison from digital hemispherical photography in boreal forests. Agricultural and Forest Meteorology 129: 187-207.

Llorens P, Gallart F. 2000. A simplified method for forest water storage capacity measurement. Journal of Hydrology 240: 131-144.

López-Moreno JI. 2005a. Recent variations of snowpack depth in the central Spanish Pyrenees. Arctic, Antarctic, and Alpine Research 37 $253-260$.

López-Moreno JI. 2005b. Disponibilidad de recursos hídricos y gestión de los embalses en el Pirineo Central Español: Interacciones entre variabilidad espacio-temporal de los recursos y el uso del agua bajo condiciones de cambio ambiental (Availability of water resources and reservoir management in the central Spanish Pyrenees). $\mathrm{PhD}$ thesis, University of Zaragoza.

López-Moreno JI, García-Ruiz JM. 2004. Influence of snow accumulation and snowmelt processes on the distribution of streamflow in the central Spanish Pyrenees. Journal of Hydrological Sciences 49: 787-802. 
López-Moreno JI, Nogués-Bravo D. 2005. A generalized additive model for the spatial distribution of snowpack in the Spanish Pyrenees. Hydrological Processes 19: 3167-3176.

López Moreno JI, Nogués Bravo D. 2006. Interpolating snow depth data: a comparison of methods. Hydrological Processes 20: 2217-2232. DOI: $10 \cdot 1002 /$ hyp.6199.

Lundberg A, Halldin S. 2001. Snow interception evaporation. Review of measurement techniques, processes, and models. Theoretical and Applied Climatology 70: 117-133.

Lundberg A, Nakai Y, Thunehed H, Halldin S. 2004. Snow accumulation in forests from ground and remote-sensing data. Hydrological Processes 18: 1941-1955.

Marks D, Kimball J, Tingey D, Link T. 1998. The sensitivity of snowmelt processes to climate conditions and forest cover during rain-on-snow: a case study of the 1996 Pacific Northwest flood. Hydrological Processes 12: 1569-1587.

Mellander PE, Laudon H, Bishop K. 2005. Modelling variability of snowdepths and soil temperatures in Scots pine stands. Agricultural and Forest Meteorology 133: 109-118.

Melloh RA, Hardy JP, Bailey N, Hall TJ. 2002. An efficient snow albedo model for the open and subcanopy. Hydrological Processes 16: 3571-3584.

Metcalfe RA, Buttle JM. 1995. Controls of canopy structure on snowmelt rates in boreal forest basin. Proceedings of the Eastern Snow Conference 54: 249-257.

Montserrat JM. 1992. Evolución glaciar y postglaciar del clima y la vegetación en la vertiente sur del Pirineo: estudio palinológico (Evolution of glacial and postglacial climate in the meridional Pyrenees: palynological study). Monografías del Instituto Pirenaico de Ecología, CSIC No. 6, CSIC, Zaragoza.

Murray CD, Buttle JM. 2003. Impacts of clearcut harvesting on snow accumulation and melt in a northern hardwood forest. Journal of Hydrology 271: 197-212.
Niu GY, Yang ZL. 2004. Effects of vegetation canopy processes on snow surface energy and mass balances. Journal of Geophysical Research 109: D23111.

Pomeroy JW, Granger RJ. 1997. Sustainability of the western Canadian boreal forest under changing hydrological conditions. I. Snow accumulation and ablation. In Sustainability of Water Resources under Increasing Uncertainty, Rosberj D, Boutayeb NE, Gustard A, Kundzewicz ZW, Rasmusen (eds). IAHS Publication No. 240. IAHS Press: Wallingford; 237-242.

Pomeroy JW, Gray DM. 1995. Snow accumulation, relocation and management. NHRI Science Report No. 7, Environment Canada, Saskatoon, SA.

Pomeroy JW, Parviainen J, Hedstrom N, Gray DM. 1998. Coupled modelling of forest snow interception and sublimation. Hydrological Processes 12: 2317-2337.

Pomeroy JW, Gray DM, Hedstrom NR, Janowicz JR. 2002. Prediction of seasonal snow accumulation in cold climate forests. Hydrological Processes 16: 3543-3558.

Richman MB. 1986. Rotation of principal components. Journal of Climatology 6: 29-35.

Talbot J, Plamondon AP, Lévesque D, Aubé D, Prévos M, Chazalmartin F, Gnocchini M. 2006. Relating snow dynamics and balsam fir stand characteristics, Montmorency Forest, Quebec. Hydrological Processes 20: 1187-1199.

White D, Richman H, Yarnal B. 1991. Climate regionalization and rotation of principal components. International Journal of Climatology 11: $1-25$

Yang D, Woo MK. 1999. Representativeness of local snow data for large scale hydrologic investigations. Hydrological Processes 13: 1977-1988. 